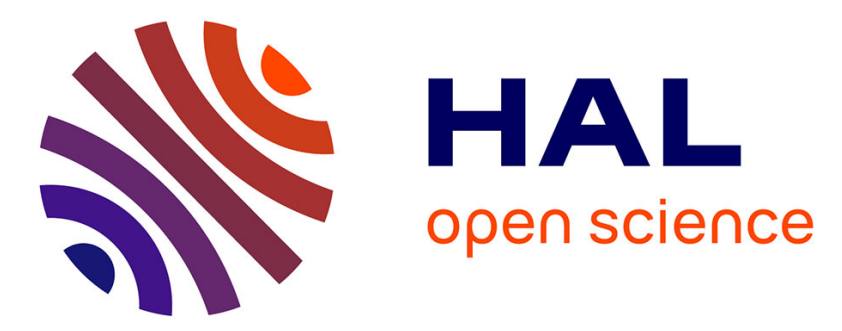

\title{
Internal erosion in granular media: direct numerical simulations and energy interpretation
}

Sibille Luc, Franck Lominé, Philippe Poullain, Yacine Sail, Didier Marot

\section{To cite this version:}

Sibille Luc, Franck Lominé, Philippe Poullain, Yacine Sail, Didier Marot. Internal erosion in granular media: direct numerical simulations and energy interpretation. Hydrological Processes, 2015, 29 (9), pp.2149-2163. 10.1002/hyp.10351 . hal-01299532

HAL Id: hal-01299532

https://hal.univ-grenoble-alpes.fr/hal-01299532

Submitted on 7 Apr 2016

HAL is a multi-disciplinary open access archive for the deposit and dissemination of scientific research documents, whether they are published or not. The documents may come from teaching and research institutions in France or abroad, or from public or private research centers.
L'archive ouverte pluridisciplinaire HAL, est destinée au dépôt et à la diffusion de documents scientifiques de niveau recherche, publiés ou non, émanant des établissements d'enseignement et de recherche français ou étrangers, des laboratoires publics ou privés. 


\title{
Internal erosion in granular media: direct numerical simulations and energy interpretation
}

\author{
Sibille Luc ${ }^{\mathrm{a}, \mathrm{b}, *}$, Franck Lominéc ${ }^{\mathrm{c}}$ Philippe Poullain ${ }^{\mathrm{a}}$, Yacine Sail ${ }^{\mathrm{a}}$, Didier Marot $^{\mathrm{a}}$ \\ ${ }^{a}$ LUNAM University, GeM Institute, CNRS, Nantes / Saint-Nazaire, France \\ ${ }^{b}$ Grenoble Université - 3SR Laboratory - UJF-INPG-CNRS, Grenoble, France \\ ${ }^{c}$ INSA Rennes - LGCGM - EA 3913, Rennes, France
}

\begin{abstract}
Internal erosion in soils is characterized by a first step of detachment of solid particles from the granular skeleton under the action of a water seepage; then the detached particles are transported with the water flow. For some erosion processes, as suffusion, transported particles may finally be redeposited within the interstitial space of the soil itself acting as a filter. This paper focuses on the analysis and the description of the two first steps of particle detachment and transport in the cases of erosion by suffusion and piping erosion. The analysis is mainly based on direct numerical simulations performed with a fully coupled discrete element-lattice Boltzmann method (DE-LB method). Inter-particle interactions occurring in the solid granular phase are described with the discrete element method, whereas dynamics of the water flow is solved with the lattice Boltzmann method. Simulation results show that internal erosion of the solid phase can be described either from the hydraulic shear stress or from the power expended by the water seepage. The latter description based on the flow power is finally compared with experimental results from laboratory tests.
\end{abstract}

Keywords: internal erosion, suffusion, discrete element method, lattice Boltzmann method, flow power

\section{Introduction}

The durability of water retaining structures made of soils such as dams and dikes, or stability of natural or man-made slopes can be compromised by the development of internal soil erosion. The latter can affect, at least locally, the hydraulic and mechanical properties of the constituting soil. The definition of the relevant parameters, easily identifiable in an engineering context, fixing the kinetics of erosion processes is still a challenging question.

Concerning water retaining structures and their foundations four main types of internal erosion can be distinguished (Fell and Fry, 2007; Bonelli, 2012): (i) concentrated leak erosion, i.e. the water erodes a crack, a hole or a hollow; (ii) backward erosion appearing mainly in soil of foundations and progressing from the

${ }^{*}$ Corresponding author: luc.sibille@3sr-grenoble.fr 
free surface in the downstream side of soil structures; (iii) suffusion (also named internal instability), which takes place inside the soil matrix; and (iv) contact erosion occurring at an interface between a fine soil layer and another layer made of a coarser soil. In the latter case, the water flow is concentrated within the coarse soil because of an higher hydraulic conductivity than that of fine soil. To come back on the erosion by suffusion, it may develop in the soil bulk when the particle size grading and the porosity are such that the fine fraction of the soil can migrate through the skeleton formed by the coarse fraction (i.e. when fine particles can pass through the constrictions of the granular skeleton of the coarse fraction) (Sjah and Vincens, 2013). For all internal erosion processes, solid particles are firstly detached by the action of a hydraulic loading, and secondly transported by the (interstitial) water flow. However, for the suffusion (or even for the contact erosion (Béguin, 2011)) there may be a third step of filtration when transported particles are redeposited within the interstitial space of the soil itself (possibly resulting in a clogging of this interstitial space) (Sail et al., 2011; Reddi et al., 2000). Note that suffusion can be described at the microscopic scale as a concentrated leak erosion problem. In this case, each pore of the soil is represented as a pipe filled of water (Bonelli and Marot, 2011). Then particle detachment occurs on the peripheral surface of the pipe and results in a shift of the soil-water interface (i.e. a local increase of the pipe diameter).

Contact erosion and concentrated leak erosion (as piping erosion) are often described by means of the hydraulic shear stress considered as the hydraulic parameter fixing the erosion regime (Beguin et al., 2013; Wan and Fell, 2004; Bonelli and Brivois, 2008; Haghighi et al., 2013). Concerning suffusion a broader variety of hydraulic parameters have been suggested to describe the hydraulic loading inducing erosion, such as the hydraulic shear stress (Reddi et al., 2000), the pore fluid velocity (Perzlmaier, 2007), the local hydraulic gradient (Moffat and Fannin, 2006), or more simply the global hydraulic gradient (Skempton and Brogan, 1994). More recently, some authors suggested to model the hydraulic loading from an energetic approach (Steeb and Diebels, 2003), for both suffusion (Marot et al., 2012; Rogoz, 1985), and piping erosion (Regazzoni and Marot, 2013; Marot et al., 2011). Erosion is then considered as driven by the flow power, i.e. the total power consumed by the fluid to seep through the soil. An advantage of such an approach could be constituted by the direct estimation of the flow power through a soil sample or a soil structure (as a dam or a dike). This power can indeed be computed from the hydraulic gradient and an estimation of the seepage flow rate; whereas the estimation of the hydraulic shear stress or the pore fluid velocity for instance, requires information and hypotheses about the soil micro-structure. Moreover, the time integration of flow power (i.e. the energy expended by the water seepage) could give an indication about the hydraulic loading history (Nguyen et al., 2012).

Besides, there is currently an important effort to develop coupled numerical methods to describe fluidsolid interactions in dense granular matter at a small scale (i.e. at the scale of a grain or an aggregate of grains) (Lominé et al., 2013; Chareyre et al., 2012; Araújo et al., 2006; Zeghal and El Shamy, 2004). For that, an option is to associate the discrete element (DE) method (Cundall and Strack, 1979) to describe 
the dynamics of the granular solid phase, and the lattice Boltzmann (LB) method (Succi, 2001) to solve the interstitial fluid flow. With such a coupling (Feng et al., 2007; Lominé et al., 2013) interactions between the solid and fluid phases are described at the scale of solid particles and result from the integration, over the solid boundaries, of the momentum exchange between solid and fluid phases. Consequently, assumptions about fluid-solid interactions are considerably reduced and only few mechanical parameters are introduced (Lominé et al., 2013).

Therefore, the objective of the paper is to discuss of the ability to describe internal erosion in granular matter from an energetic approach, on the basis of direct numerical simulations of piping erosion performed with a DE-LB coupled method. Nevertheless, suffusion is also addressed by analyzing experimental results from laboratory tests.

The DE-LB coupled method has been presented in (Lominé et al., 2013), the numerical method is thus only briefly introduced in the first section of the paper, together with the two-dimensional numerical model of piping erosion. In a second section, the results of simulations of piping erosion are interpreted in a classical way, under the assumption that the detachment and transport of solid particles are driven by the hydraulic shear stress. Finally the third section constitutes the central part of the article where the interpretation of internal erosion in the framework of an energetic approach is investigated, for both piping erosion (by considering the simulations and a laboratory test) and some suffusion tests. In this objective, energetic terms related to the flow of a fluid within a saturated granular assembly are presented. Then the ability to describe the detachment and transport of solid particles in internal erosion problems via some energetic terms, such as the flow power, is discussed.

\section{DE-LB numerical model}

The coupled discrete element - lattice Boltzmann method has been extensively presented in (Lominé et al., 2013) and here we give only the details necessary for the understanding and interpretation of results. The granular solid phase is described with a classical discrete element method (DE method) as introduced by Cundall and Strack (Cundall and Strack, 1979). Particles are circular and their interactions are described with a frictional cohesive contact interaction law as represented in Figure 1. In the elastic regime the contact law is characterized by linear stiffnesses $k_{n}$ and $k_{s}$ related to the normal and shear (or tangential) contact directions respectively. In the shear direction plastic sliding occurs when the shear force $F_{s}$ reaches the Mohr-Coulomb criterion as represented in Figure 1a and characterized by the contact friction angle $\phi_{c}$ and the shear cohesion $C_{s}$. When sliding occurs the inter-particle cohesion is broken, then shear and normal cohesions, $C_{s}$ and $C_{n}$ are set to zero and the contact becomes purely frictional. In the normal direction, tensile normal force $F_{n}$ is allowed until a limit value defined by the normal cohesion $C_{n}$. When this limit is 
reached the contact is lost. Generally speaking the contact cohesion is brittle, hence if an initial contact is broken, particles engaged in this contact will have the possibility to make new contacts between themselves or with other particles, but these new contacts will be purely frictional (and not cohesive).

Fluid dynamics is fully described between solid particles with the lattice Boltzmann method (LB method) (Succi, 2001). As the model developed is a two-dimensional one, the common D2Q9 discretization scheme (Qian et al., 1992) was used in association to the BGK collision operator (Bhatnagar et al., 1954; Chen et al., $1992)$ for the application of the LB method. The ratio between mean solid particle diameter $d_{\text {mean }}$ and the lattice space $h$ is about $d_{\text {mean }} / h \approx 17$. The space discretization of the fluid domain is therefore relatively fine. A full coupling was implemented between the DE and the LB methods. Action of the solid phase on the fluid phase is taken into account thanks to a modified bounce-back rule (Ladd, 1994). By this way, the fluid domain boundary fits the solid particle shape and transfer of momentum from a moving solid particle to the fluid is considered. Action of fluid on solid particles is described by adding the hydraulic force and torque (corresponding to the action of fluid pressure and viscous stresses over each solid particle surface) to the resultant inter-particle contact force and torque acting on each grain. Details of the computation of these hydraulic force and torque are given in (Lominé et al., 2013). We just recall here that they are deduced from the time derivation of the momentum exchange between fluid and solid phase, and the only assumption made for this computation is the no-slip condition of fluid on solid surface and no parameter is introduced. Consequently the mechanical parameters introduced in the coupled method are the fluid viscosity $\nu$, and the parameters of the contact interaction law between solid particles (stiffnesses, cohesions, and friction angle). The values of these parameters are given in Table 1 .

The numerical model presented in Figure 2 consists of a two-dimensional rectangular assembly of circular solid particles. The mean solid particle diameter is $d_{\text {mean }}=4.7210^{-4} \mathrm{~m}$, with a slight size dispersion $\left(d_{\max } / d_{\min }=1.93\right)$. Particles in the central part of the assembly are removed to create an initial hole with a width $d_{h}$ about four times larger than $d_{\text {mean }}$. Contacts generated between particles (and between particles and walls) in this initial configuration are all cohesive contacts such that $C_{s}=C_{n}=C$. Granular assemblies characterized by seven different values of cohesion will be considered: $C / d=0.152 ; 0.177 ; 0.253$; $0.506 ; 1.27 ; 2.53$ and $12.7 \mathrm{~N} / \mathrm{m}$. These granular assemblies are placed within a channel where boundary fluid conditions correspond to no-flow and no-slip conditions on top and bottom boundaries (i.e. rigid horizontal walls). Pressure conditions are imposed on left (inlet) and right (outlet) boundaries to create a water flow under the pressure drop applied. Simulations were carried out with different pressure drop values ranging from 0.01 to $0.50 \mathrm{~Pa}$, leading to a Reynolds number comprised between 0.50 and 40.0. Gravity is not taken into account. Depending on the contact cohesion and the pressure drop, solid particles may detach from the granular skeleton. They are then carried by the fluid towards the right boundary of the simulation domain (i.e. the outlet), as illustrated in Figure 3. 
The mass of particles getting out of the simulation domain is added up and is defined here as the cumulative eroded mass $M_{e}$. Typical time series of the ratio $M_{e} / M_{0}$ (where $M_{0}$ is the initial mass of the granular skeleton) are shown in Figure 4. For the highest pressure drop values the eroded mass reaches a plateau at an eroded ratio $M_{e}(t) / M_{0} \approx 0.9$. Since the number of particles constituting the granular assembly is finite, the ratio of eroded mass is obviously limited to a maximum of 1 . However, for all simulations we observed particles remaining glued to the bottom and top horizontal walls even for the high pressure drops explaining why the eroded mass ratio never reached the value of one. The decrease in the rate of eroded mass just before reaching the plateau and the plateau itself (Fig. 4) are not typical of the erosion process studied here. This is actually related to the finite size of the problem and the limitation of the number of solid particles available. Therefore data corresponding to the final decrease of the erosion rate will be discarded in the following analysis.

We investigate in the following two phenomenological ways to interpret these numerical results that could be of interest for internal erosion description in an engineering context. These interpretations differ from the description of the hydraulic loading, either through the hydraulic shear stress or via the flow power, fixing the erosion rate.

\section{Shear stress driven erosion}

A common description of the hydraulic loading for piping and contact erosion is to consider that erosion depends on the hydraulic shear stress $\tau_{s}$ applied by the fluid on the fluid/solid interface. In particular laboratory hole erosion test (Wan and Fell, 2004; Haghighi et al., 2013) from which the presented numerical model is inspired, are interpreted from the erosion law:

$$
\dot{\epsilon}=k_{d}\left(\tau_{s}-\tau_{c}\right) \quad \text { if } \tau_{s}>\tau_{c}
$$

where $\dot{\epsilon}$ is the rate of eroded mass per unit of erosion surface area, and $k_{d}$ and $\tau_{c}$ are two parameters characterizing the sensitivity of the soil to erosion. $\tau_{c}$ represents a critical stress below which erosion does not occur; the erosion coefficient $k_{d}$ characterizes the kinetics of the phenomenon. Note that similar expressions, maybe more developed, can be found in the framework of scour and sediment transport (Briaud et al., 2001; Partheniades, 1965; Parchure and Mehta, 1985; Govers, 1992; Ferro, 1998). Besides such a shear stress driven erosion has already been considered in the case of particle detachment in suffusion in soils (Bonelli and Marot, 2011), where each pore of the soil can be represented as a pipe, and the solid particle detachment from the peripheral surface of the pore as a piping erosion problem.

Hydraulic shear stress $\tau_{s}$ at the boundaries of the hole can be estimated from the cross profiles of the 
fluid velocity inside the hole by computing:

$$
\tau_{s}=\nu \rho_{0}\left|\frac{\partial v_{x}}{\partial y}\right|
$$

However, as the roughness of the hole surface is quite important with respect to the hole size, velocity profiles and hole diameter may differ from one cross section to another. Consequently, as illustrated in Figure 5, it has been decided to average the velocity cross profiles along the length of the hole, and to assume that points of maximum shear rate (i.e. maximum of velocity gradient $\partial v_{x} / \partial y$ ) on both sides of this averaged velocity profile correspond to the mean position of hole boundaries. Therefore, these latter maximum values of $\partial v_{x} / \partial y$ have been chosen to compute $\tau_{s}$ according to Equation 2.

Plots of the erosion rate $\dot{\epsilon}$ with respect to the hydraulic shear stress is shown in Figure 6 for a unique granular assembly (characterized by a unique inter-particle cohesion $C / d=0.506 \mathrm{~N} / \mathrm{m}$ ), and for ten simulations differing from the applied pressure drop ranging from 0.01 to $0.50 \mathrm{~Pa}$. For the numerical model developed, Figure 6 shows that the erosion rate $\dot{\epsilon}$ is linearly related to $\tau_{s}$ as expressed by Equation 1. Erodability properties of the granular assembly for $C / d=0.506 \mathrm{~N} / \mathrm{m}$ are then determined using a linear regression: $\tau_{c}=6.78 \times 10^{-4} \mathrm{~Pa}$ and $k_{d}=9.07 \mathrm{~s} / \mathrm{m}$.

We recall that the linear relation found here is not influenced by some fluid-solid interaction parameters since none are introduced in the model as explained in Section 2. Therefore, erosion rate may be influenced only by either the properties of the solid granular phase, or those of the fluid phase.

In the following, a brief parametric study is conducted by performing simulations for seven values of inter-particle cohesion $C / d=0.152 ; 0.177 ; 0.253 ; 0.506 ; 1.27 ; 2.53$ and $12.7 \mathrm{~N} / \mathrm{m}$, tested under five to ten pressure drops $\Delta P$ ranging from 0.01 to $0.50 \mathrm{~Pa}$. Critical shear stress $\tau_{c}$ and erosion coefficient $k_{d}$ identified for each cohesion value are plotted in Figure 7.

For the highest inter-particle cohesion value $C / d=12.7 \mathrm{~N} / \mathrm{m}$, corresponding to the last point of plots in Figure $7 \mathrm{a} \& \mathrm{~b}$, erosion has not been triggered, not even for the highest pressure drop $\Delta P=0.50$ Pa. Consequently the value of $\tau_{c}$ identified in this case represents only the highest hydraulic shear stress applied to the granular assembly and not a yield value beyond which erosion occurs, and the erosion coefficient cannot be determined as suggested in Figure 7b. Besides, for the three lowest values of cohesion, corresponding to the three first points of plots in Figure 7a \& b, the contact cohesion is broken in the bulk of the granular assembly at the initiation of the fluid flow, instead of being progressively broken for solid particles at the vicinity of the hole, as the diameter of the latter grows with the detachment of particles. This is due to a water hammer occurring at the initiation of the flow, generating a shock wave breaking the too brittle granular assemblies. This is illustrated in Figure 8 where the ratio of the number of purely frictional contacts $N c_{\phi}$ (i.e. contacts for which initial cohesion has been broken) over the total number of contacts 
$N_{c}$ is plotted for the first second of simulation. Before initiation of the water flow all the contacts are cohesive and $N c_{\phi} / N c=0$. For low cohesion values, for instance $C / d=0.152 \mathrm{~N} / \mathrm{m}$, almost all the cohesive contacts are broken just after flow initiation with the ratio $N c_{\phi} / N c$ reaching a value of about 0.9 . On the other hand, for a sufficiently high inter-particle cohesion, $C / d=1.27 \mathrm{~N} / \mathrm{m}$, less than $20 \%$ of the cohesive contacts are broken after flow initiation, other contacts being broken progressively around the hole all along the simulation. Consequently, when the inter-particle cohesion is low, this one is lost when flow starts and the granular assembly behaves essentially as a cohesionless material. The values of $\tau_{c}$ for the three lowest cohesion values (Figure 7) should therefore be considered carefully and would be more likely representative of a cohesionless granular assembly than a weakly cohesive material.

Despite limitations discussed above, the erosion coefficient $k_{d}$ seems independent of the cohesion of the solid phase whereas the critical shear stress $\tau_{c}$ seems directly affected by the cohesion. Unfortunately we cannot conclude from the numerical data presented here about the shape of the relation between $C$ and $\tau_{c}$.

\section{Flow power driven erosion}

Marot et al. (2012) and Regazzoni and Marot (2013) suggested that internal erosion in soils could be driven by the power dissipated by the fluid flow throughout the porous solid phase. The use of flow power (or stream power) to characterize the transport of sediments in the bed of rivers has been suggested since the 1950s by Bagnold (Bagnold, 1956, 1980), but also more recently for overland flow sediment transport (Govers, 1992; Low, 1989; Ferro, 1998). In both cases (river and overland flow) the stream power is defined as the product between the hydraulic shear stress on the bed soil and the mean flow velocity, giving an estimation of the power dissipated by viscous shear in the fluid. In the expressions proposed the sediment transport rate is generally not a linear relation of the stream power, but a power function of the stream power according to Bagnold (Bagnold, 1980) and Govers (Govers, 1992).

Besides, it is generally accepted that internal erosion in soils comprises three steps (Reddi et al., 2000): detachment of solid particles from the initial granular skeleton, their transport within the interstitial space, and eventually a possible deposition (or filtration) of the transported particles in soil pores. In the framework of sediment transport in rivers and overland flow there is no filtration step and expressions discussed above aim more particularly to characterize only the detachment and transport of particles (note that for overland flow, step of detachment is often related to the impact of rain on the soil and thus may be described separately).

The analysis carried out in this paper, in the framework of internal erosion, is voluntarily limited to the steps of detachment and transport for the sake of separation of problems, and the process of deposition is discarded. The discrete numerical model has indeed been designed to avoid deposition or filtration, since even if some particles may temporarily settle, detachment and transport are far more predominant with an 
irreversible increase of the hole width. In this section we investigate the possibility to describe the hydraulic loading causing the detachment and the transport of solid particles with the flow power (or at least with some power terms). This investigation is based on the numerical model presented in Section 2 and some experimental results. Nevertheless we begin first by presenting the different energetic terms related to the flow of a fluid within a deformable granular material.

\subsection{Energy conservation equation}

We consider the flow of a viscous fluid of volume $V$ limited by a boundary surface $S$ with outer unit normal vector $\vec{n}$. We define at a position $\vec{x}$ of this volume, the fluid density $\rho$, its static pressure $p$ and velocity $\vec{v}$, and the tensor of viscous stresses $\overline{\bar{\sigma}}^{v}$. If the only body force applied to the fluid is the gravity $\vec{g}$, then the energy conservation equation within volume $V$ writes (Guyon et al., 2001):

$$
\begin{aligned}
\frac{d}{d t}\left(\int_{V} \rho \frac{v^{2}}{2} d V\right)= & -\int_{S} \rho \frac{v^{2}}{2} \vec{v} \cdot \vec{n} d S \quad-\int_{S} p \vec{v} \cdot \vec{n} d S \\
& +\int_{S}\left(\overline{\bar{\sigma}}^{v} \cdot \vec{n}\right) \cdot \vec{v} d S \quad+\int_{V} \rho \vec{g} \cdot \vec{v} d V \\
& -\int_{V} \sigma_{i j}^{v} \frac{\partial v_{i}}{\partial x_{j}} d V .
\end{aligned}
$$

Hence the change of kinetic energy of the fluid (left hand side of Equation 3) depends on the global flux of kinetic energy $\rho \frac{v^{2}}{2}$ carried by the fluid through the surface $S$; the work of pressure forces and of viscous stresses on the boundary $S$ of the fluid volume; the work of the gravity body force in volume $V$; and finally the irreversible transformation of kinetic energy into heat corresponding to the power dissipated by the work of viscous stresses in the fluid bulk.

For a seepage within a granular assembly the boundary of the fluid volume is actually constituted of two complementary surfaces as presented in Figure 9a: the outer boundary $S_{D}$ of the fluid domain of normal $\vec{n}_{D}$, and the boundary at the interface with solid grains called $S_{G}$, of normal $\vec{n}_{G} . S_{D}$ is a fixed surface whereas $S_{G}$ is mobile, since solid grains can move; in addition $S_{D}$ and $S_{G}$ are complementary such that $S_{D} \cup S_{G}=S$. Then conservation energy equation can be rewritten as:

$$
\begin{aligned}
\int_{S_{D}} & {\left[-\rho \frac{v^{2}}{2} \vec{v} \cdot \vec{n}_{D}-p \vec{v} \cdot \vec{n}_{D}+\left(\overline{\bar{\sigma}}^{\prime} \cdot \vec{n}_{D}\right) \cdot \vec{v}\right] d S=} \\
& \int_{S_{G}}\left[\rho \frac{v^{2}}{2} \vec{v} \cdot \vec{n}_{G}+p \vec{v} \cdot \vec{n}_{G}-\left(\overline{\bar{\sigma}}^{v} \cdot \vec{n}_{G}\right) \cdot \vec{v}\right] d S \\
& -\int_{V} \rho \vec{g} \cdot \vec{v} d V+\int_{V} \sigma_{i j}^{v} \frac{\partial v_{i}}{\partial x_{j}} d V+\frac{d}{d t}\left(\int_{V} \rho \frac{v^{2}}{2} d V\right)
\end{aligned}
$$

For an established flow regime, change of kinetic energy over the whole fluid domain becomes negligible and we can assume that $\frac{d}{d t}\left(\int_{V} \rho \frac{v^{2}}{2} d V\right)=0$. In addition, there is no flux of kinetic energy through an 
impermeable surface. In other words, if the impermeable surface is mobile then the velocity $\vec{v}$ to take into account in the convective term of kinetic energy through this surface, is the relative velocity of the fluid with respect to this surface. As the surface of grains is impermeable the relative velocity on $S_{G}$ is vanishing and $\int_{S_{G}} \rho \frac{v^{2}}{2} \vec{v} \cdot \vec{n}_{G} d S=0$.

To go further, we now take into account the geometry of the fluid volume considered in the numerical model (and also in laboratory tests discussed at the end of this paper) corresponding to a tube of constant diameter with an impermeable lateral surface $S_{l}$, and delimited by inlet $S_{i}$ and outlet $S_{o}$ surfaces, as illustrated in Figure 9b. Consequently, $S_{D}=S_{l} \cup S_{i} \cup S_{o}$. For a weakly compressible fluid the transfer of kinetic energy is almost balanced between $S_{i}$ and $S_{o}$. In addition, if we assume on $S_{i}$ and $S_{o}$ a fluid velocity normal to these surfaces, then the work of viscous stresses on $S_{i}$ and $S_{o}$ is negligible. Finally, $S_{l}$ is impermeable with a no slip condition, consequently conservation energy equation expresses:

$$
\begin{aligned}
& -\int_{S_{i}} p \vec{v} \cdot \vec{n}_{i} d S-\int_{S_{o}} p \vec{v} \cdot \vec{n}_{o} d S= \\
& \quad \int_{S_{G}}\left[p \vec{v} \cdot \vec{n}_{G}-\left(\overline{\bar{\sigma}}^{v} \cdot \vec{n}_{G}\right) \cdot \vec{v}\right] d S-\int_{V} \rho \vec{g} \cdot \vec{v} d V+\int_{V} \sigma_{i j}^{v} \frac{\partial v_{i}}{\partial x_{j}} d V
\end{aligned}
$$

Using the divergence theorem (for negligible fluid volume changes):

$$
\int_{V} \rho \vec{g} \cdot \vec{v} d V=-\int_{S_{i}+S_{o}} \rho g z \vec{v} \cdot \vec{n} d S-\int_{S_{G}} \rho g z \vec{v} \cdot \vec{n}_{G} d S
$$

Finally, the power of the fluid flow through the granular assembly is:

$$
\begin{gathered}
-\int_{S_{i}}\left[p \vec{v} \cdot \vec{n}_{i}+\rho g z \vec{v} \cdot \vec{n}_{i}\right] d S-\int_{S_{o}}\left[p \vec{v} \cdot \vec{n}_{o}+\rho g z \vec{v} \cdot \vec{n}_{o}\right] d S= \\
\int_{S_{G}}\left[p \vec{v} \cdot \vec{n}_{G}-\left(\overline{\bar{\sigma}}^{v} \cdot \vec{n}_{G}\right) \cdot \vec{v}+\rho g z \vec{v} \cdot \vec{n}_{G}\right] d S+\int_{V} \sigma_{i j}^{v} \frac{\partial v_{i}}{\partial x_{j}} d V
\end{gathered}
$$

The left hand side of Equation 7 (sum of integrals over $S_{i}$ and $S_{o}$ ) represents the power supplied to the fluid to flow within the granular assembly. In the following we will call this term the flow power $P_{F}$. The integral over surface $S_{G}$, that will be denoted $I_{G}$, represents the power transfered from the fluid to the solid particles, and the remaining volume integral is the power dissipated by viscous stresses in the bulk $P_{V}$. Then:

$$
P_{F}=I_{G}+P_{V}
$$

Note that as long as solid grains do not move, fluid velocity $\vec{v}$ on $S_{G}$ is nil and there is no energy transfer from fluid to solid.

\subsection{Power transfer from the fluid to the solid phase}

Term $I_{G}$ could be interpreted as the erosion power, i.e. the power term fixing the erosion regime. It is interesting to note that this term includes the work of viscous stresses relative to the viscous shear stress 
appearing in some classical erosion laws as the one in Equation 1, but also the work of pressure forces. We can imagine the latter pressure term plays an important role in internal erosion when clogging occurs due to an important filtration and that overpressure develops consecutively upstream from this clogging. However, energetic expressions used to describe solid transport in river and overland flow do not involve this term $I_{G}$ but are generally based on an estimation of the power dissipated by viscosity in the flow close to the solid bed.

In order to estimate the importance of the term $I_{G}$ with respect to the flow power $P_{F}$ during internal erosion of soils, we performed a rough estimation of $I_{G}$ from experimental results. For that, it is assumed that the power $I_{G}$ is used to transport detached solid particles, acquiring by this way some kinetic energy. We consider for instance the suffusion tests performed by Marot et al. (2009) on mixtures of sand and clay, and in particular the sample numbered 5 in (Marot et al., 2009) subjected to a hydraulic gradient $i=8$. For this sample, the hydraulic conductivity $k$ is about $510^{-6} \mathrm{~m} / \mathrm{s}$ corresponding to a flow rate $Q=7.8510^{-8} \mathrm{~m}^{3} / \mathrm{s}$. Hence the flow power can be estimated at about $P_{F}=i L \gamma_{W} Q=3.1410^{-4} \mathrm{~W}$ (where $L$ is the length of the sample equal here to $5 \mathrm{~cm}$ and $\gamma_{W}=10 \mathrm{kN} / \mathrm{m}^{3}$ is the specific weight of water). The highest erosion rate measured for this test is $q_{s}=0.9 \mathrm{mg} / \mathrm{s}$, and we assume the solid particle velocity equals the pore fluid velocity computed as $v_{p}=Q /(S . n)=1.2110^{-4} \mathrm{~m} / \mathrm{s}$, where $n=0.33$ is the initial porosity of the sample and $S$ its cross section area (with a diameter of $5 \mathrm{~cm}$ ). Hence the kinetic power of the solid particles in the effluent is estimated equal to $P k_{\text {solid }}=1 / 2 q_{s} v_{p}^{2}=6.5910^{-14} \mathrm{~W}$. In addition we suggest that a very rough indication of the power required for the transport of detached solid particles within the porous sample could be given by the work of the weight of these solid particles along an upward translation in a vertical flow, at the maximum, equal to the length $L$ of the sample: $P t_{\text {solid }}=g q_{s} L=4.4110^{-6} \mathrm{~W}$.

Such a result can only represent an order of magnitude, and one can argue that a non negligible flow power is used to detach clayey solid particles and break their link with the solid skeleton. Nevertheless, these calculations have also been made from erosion tests performed by Chang and Zhang (2011) (sample numbered 2 in (Chang and Zhang, 2011)) on a mixture of fine gravel and sand (i.e. non-coherent material), and by Sail et al. (2011) on cohesionless glass bead assemblies. Results are summarized in Table 2. In all cases, transfer of power from the fluid to solid particles (assumed equal to $P k_{\text {solid }}+P t_{\text {solid }}$ ) represents about $1 \%$ of the fluid flow power $P_{F}$. Consequently, it would be difficult, from the knowledge of the sole water flow power (generally assessable in laboratory test and field soil structures) to estimate correctly the term $I_{G}$.

An analysis similar to the one conducted for suffusion tests is carried out for hole erosion tests. In this case we assume that detached solid particles reach a velocity equal to the velocity of the water inside the hole computed as $v_{h}=Q / S_{h}$ (where $S_{h}$ is the area of the hole cross section); and that particles are transported over a distance equal to the length of the soil sample. Table 3 presents the values of power terms computed from data reported in (Regazzoni and Marot, 2013) for two types of soil. The ratio between $I_{G}$ (assumed 
equal to $\left.P k_{\text {solid }}+P t_{\text {solid }}\right)$ and the flow power $P_{F}$ is here particularly sensitive to the soil erodability. If we consider the moderately erodible soil denoted TF-2 in (Regazzoni and Marot, 2013), the ratio between the estimated value of $I_{G}$ and the flow power is less than $1 \%$; whereas for a strongly erodible soil denoted L-1 the ratio is about $1 / 4$.

Finally, the terms in Equation 7 (flow power $P_{F}$, fluid-solid power transfert $I_{G}$, and power dissipated by viscosity $P_{V}$ ) can be directly computed for the numerical simulations presented in Sections 2 and 3 . Figure 10 presents the time integration of each of these terms (i.e. cumulated energy) for two simulations performed with different inter-particle cohesions $(C / d=0.253 \mathrm{~N} / \mathrm{m}$ and $2.53 \mathrm{~N} / \mathrm{m})$. As for the hole erosion test discussed above, the ratio of $I_{G}$ to the flow power $P_{F}$ is also sensitive to the erodability of the solid phase. This ratio is about $1 / 2000$ for $C / d=2.53 \mathrm{~N} / \mathrm{m}$, and can reach up to $1 / 5$ for $C / d=0.253 \mathrm{~N} / \mathrm{m}$ (Fig. 10). These values are in agreement with the range of variation deduced from hole erosion tests.

Incidentally, it is also possible to assess the energy conservation of the fluid phase since the sum of the cumulated energies dissipated by viscosity and transferred from the fluid to the solid should be equal to the cumulated flow energy (Equation 8). For the highest inter-particle cohesion the error in the energy conservation is constant and lower than $2.5 \%$. This error slighty increases with time for the lowest cohesion value, where detachment of solid particles is much more important, to reach a maximum of $12.0 \%$ at the end of the simulation (involving more than 3 million time steps to simulate $200 \mathrm{~s}$ of physical time). In the latter case, the hole diameter increases relatively fast in relation with particle erosion, and finally higher fluid velocities are reached. Consequently, during the simulation for the lowest cohesion value, the computational Mach number grows and numerical results may slightly differ from the incompressible flow assumption (even though the maximum Mach number reached at the end of the simulation, Ma $=0.035$, is still low). In the same way, the flow slightly differs from an established flow regime with negligible changes of kinetic energy as assumed in Equations 5 to 8.

To resume, from the estimations of $I_{G}$ performed above in suffusion and hole erosion cases, it seems to be difficult in internal erosion problems to estimate the proportion of the flow power transfered to the solid phase to deform it and detach some particles, because this transfer represents a quasi negligible fraction in suffusion case, and is highly variable in piping erosion conditions. Consequently we suggest to investigate the possibility to characterize the action of fluid on solid directly from the total flow power $P_{F}$, as done in some expressions used in sediment transport in river (Bagnold, 1980) and overland flow (Govers, 1992).

Besides, the flow power $P_{F}$ seems to constitute a good representation of the fluid-solid interactions as explained below. Figure 11 displays snapshots of the field of power density dissipated by viscosity during a numerical simulation. The highest dissipation is met close to the solid particle boundaries. In addition, we integrated the viscous power density over a surface $S_{\text {limit }}$ which the extent is limited at a distance $d_{\text {limit }}$ of any particle boundary as defined in Figure 12. Figure 13 displays the ratio $P_{V}\left(\in S_{\text {limit }}\right) / P_{V}$ in terms of the 
dimensionless distance $d_{\text {limit }} / d_{\text {mean }}$ (where $d_{\text {mean }}$ is the mean particle diameter). On average, half of the viscous power is dissipated at a distance less than one third of the mean particle size. At a distance equal to the mean particle size, about $87 \%$ of the viscous power is dissipated.

Since the flow power is almost entirely dissipated by viscosity, and that viscous dissipation is concentrated at the vicinity of solid particles (constituting the sides of the hole, or for some of them already detached and transported), flow power $P_{F}$ is for such an internal flow, directly related to the fluid-solid interactions (viscous dissipation in the inlet and outlet chambers where convergent and divergent flows occur is negligible for the considered geometry, however these dissipations may be non-negligible for some geometries of hole erosion devices (Regazzoni and Marot, 2013) and should be taken into account). In addition $P_{F}$ is easily accessible from the hydraulic gradient and the conductivity of the porous medium (or a measure of the flow rate).

\subsection{Application to hole erosion}

Following the discussion developed in the previous section, the erosion rate $\dot{m}$ (mass of eroded particle per unit of time) is first plotted in terms of power dissipated by viscosity at fluid boundary nodes (FB nodes). As explained in (Lominé et al., 2013), FB nodes are the computational nodes of the fluid domain constituting its boundary on the fluid/solid interface. Hence the power dissipated by viscosity at FB nodes, $P_{V}^{F B}$, represents the power dissipation occurring most closely with the solid particles. Plots with linear and logarithmic scales are shown in Figure 14 for $C / d=1.27 \mathrm{~N} / \mathrm{m}$. The erosion rate varies as a power function of the excess power dissipated by viscosity at the direct vicinity of solid particles:

$$
\dot{m} \propto\left(P_{V}^{F B}-P_{V}^{F B *}\right)^{\alpha_{V}}
$$

where $P_{V}^{F B *}$ is the threshold value of $P_{V}^{F B}$ at which particle detachment initiates. Best fit approximation is represented with a dashed line in Figure 14 for $P_{V}^{F B *}=7.0510^{-9} \mathrm{~W}$ and $\alpha_{V}=0.75$.

As discussed earlier, the power dissipated by viscosity at the vicinity of the solid boundaries constitutes an important part of the flow power. Consequently, a relation similar to Equation 9 can be found between the erosion rate $\dot{m}$ and the flow power $P_{F}$ (simply calculated as the product between the global pressure drop and the flow rate) as shown in Figure 15. Although the scaling of the erosion rate with the flow power $P_{F}$ is slightly less satisfying than with $P_{V}^{F B}$, the erosion rate can also be expressed as:

$$
\dot{m} \propto\left(P_{F}-P_{F}^{*}\right)^{\alpha_{F}}
$$

by introducing a threshold flow power $P_{F}^{*}$. Dashed line in Figure 15 shows the best approximation for $P_{F}^{*}=7.3210^{-8} \mathrm{~W}$ and $\alpha_{F}=0.50$. Hence, numerical data suggest that rate of particle detachment can be simply related to flow power, according to a power law. This possibility assessed from numerical experiments 
is investigated from results of laboratory tests below, and in the next section for the erosion by suffusion.

Haghighi et al. (2013) performed hole erosion tests on reconstituted soils from clay-sand mixtures. The detailed data they published, concerning an exemplary test on a sample made up of $50 \%$ of kaolin clay and $50 \%$ of sand, enables to reinterpret the experimental results as suggested above. The erosion rate is plotted in terms of the flow power in Figure 16. For this experimental case the erosion rate is linearly related to the flow power as shown by the dashed line representing the Equation 10 for $\alpha_{F}=1$ and a threshold flow power $P_{F}^{*}=8.310^{-3} \mathrm{~W}$.

It is worth noting that the numerical model is only a very rough two-dimensional representation of both the three-dimensional experimental device used to perform hole erosion tests, and of the solid phase which is subjected to erosion. For instance inter-particle cohesion has been chosen to enable particle detachments under the low flow intensity described with the lattice Boltzmann method (since fluid flow velocity has been voluntarily limited as explained further in the conclusion) and not with respect to a real soil. This explains the differences of the values of the flow power threshold found with the numerical model and from the laboratory test presented in Figure 16.

\subsection{Application to suffusion from laboratory tests}

The analysis in this section is based on suffusion tests performed on two different materials. The first material is made of an assembly of glass beads, whereas the second one is a natural soil composed of sand and fines (most likely silt).

Concerning tests performed on glass beads, a detailed description of the material and the experimental device is given in (Sail et al., 2011). We only recall here the necessary elements for the development of the discussion. The glass bead assembly is a mixture of small beads with diameters ranging from 0.1 to $0.2 \mathrm{~mm}$, and bigger ones ranging from 1.2 to $3.4 \mathrm{~mm}$. Hence this is a gap graded assembly of beads with small beads constituting $40 \%$ of the total mass. A sample made with this bead assembly is realized inside an oedo-permeameter sketched in Figure 17. The sample rests on a wire mesh with a $1.25 \mathrm{~mm}$ pore opening size avoiding the migration of the biggest beads. The oedo-permeameter is constituted of a rigid cylindrical cell containing the sample, and a piston to apply a vertical stress of $25 \mathrm{kPa}$ on the sample with a pneumatic cylinder. The saturated sample is then submitted to a vertical downward water flow under a controlled hydraulic gradient, while measuring the flow rate. Beads carried with the effluent at the outlet of the cell are collected using a sampling device. A test consists in successive steps of about 60 min with a constant hydraulic gradient $i$. The value of $i$ is increased of 1 at the start of each step $(i=1 ; 2 ; 3 \ldots)$. Finally the test is stopped when the flow rate exceeds the capacity of the water supplying device. We present the results of four tests differing from the sample height: $25 \mathrm{~cm}$ (test I1-L25), $40 \mathrm{~cm}$ (tests I1-L40a and I1-L40b, 
repeatability tests), and $60 \mathrm{~cm}$ (test I1-L60).

Time series of the mass of collected beads are shown in Figure 18a. Steps of the hydraulic gradient are visible, since at the beginning of each step mass increases rapidly, and tends to stabilize at the end of the step. The decreasing of the erosion rate during a hydraulic step is related to the limitation of detachable fine beads (this limitation being itself dependent on the hydraulic gradient (Bonelli and Marot, 2011)), and the possible development of filtration (re-deposition of transported particles within the sample itself). Consequently we assume that only the erosion rate at the initiation of each step of hydraulic gradient is characteristic of particle detachment, and only this data is considered in the following. Figure 18b presents the erosion rate (computed as the slope of the eroded mass versus time at initiation of each step of hydraulic gradient) as a function of the flow power. A threshold of the flow power has not been introduced in this representation since its value is difficult to evaluate due to the low number of points. Nevertheless, it is shown that detachment of beads can be expressed as a power function of the flow power characterized with an exponent 1.67 .

We performed a similar analysis from suffusion tests performed on a natural soil and reported in (Sterpi, 2003) (where details of the experiment can be found). The soil consisted of continuously graded sand and fines. Fines mainly composed of silt represent initially $23 \%$ of the total dry mass. The principle of the erosion test is basically similar to the one decribed for glass beads in Figure 17, excepted the flow oriented here in the upward direction. Eroded particles are then collected at the top of the soil sample. Five tests performed at five different constant hydraulic gradients, $i=0.18 ; 0.39 ; 0.55 ; 0.60$; and 0.75 , are reported. Percentage by weight $\mu_{e}$ of eroded fine particles with time is shown in Figure 19a. As for tests with glass beads we consider only the erosion rate at the initiation of each test, and flow power at this time has been estimated by assuming an hydraulic conductivity $k=510^{-5} \mathrm{~m} / \mathrm{s}$ (slightly lower than the conductivity reported in (Sterpi, 2003), but determined on the original soil containing coarser elements than the one used for the tests). Erosion rate in terms of flow power $P_{F}$ at test initiations is displayed in Figure 19b. Although range of values is quite reduced, data are well described by a power law with an exponent about 1.5 , excepted for the highest hydraulic gradient $i=0.75$. In this last case, only a lower boundary of the slope of the mass vs time curve (i.e. of the erosion rate) is accessible, due the very low number of experimental points (Figure 19a).

Consequently, as for the numerical simulations of hole erosion, experimental data presented above for the suffusion support the description of the detachment and transport of solid particles in terms of the water flow power. This holds at the initiation of the suffusion tests; for larger time period this description need to be completed to take into account the filtration step. 


\section{Conclusion}

Numerical experiments of hole erosion were performed with a DE-LB coupled method. This numerical method presents the advantages to limit the hypotheses introduced to describe the fluid-solid interactions, and to involve few mechanical parameters (one for the fluid phase, four for the solid phase, and none for the fluid-solid interactions). In addition, the fluid flow is described at a scale smaller than the pore or the particle scale. On the other hand, the computation cost is important, and conditions to satisfy a low Mach number, and thus a low compressibility, may be quite restrictive in some configurations. Furthermore, to facilitate this first numerical approach, imposed pressure drops, and thus fluid velocities, have been kept voluntarily small to consider only laminar flows with a Reynolds number comprised between 0.50 and 40.0. Consequently, the described flow regime should be in agreement with the water seepage involved in suffusion processes usually characterized by a low Reynolds number (for instance $R e=0.25$ for a clayey sand according to Marot et al. (2012)), but it is quite far from what is expected in hole erosion tests, usually characterized by turbulent flows with a Reynolds number from 2,000 up to 20,000 (Bonelli, 2012). The latter point constitutes a restriction of the numerical model which could be removed in future enhanced simulations.

Despite these limitations, numerical experiments of piping erosion can be interpreted similarly to laboratory hole erosion tests where the erosion rate is linearly related to the hydraulic shear stress. A brief parametric study showed that the erosion threshold depends on the cohesion of the granular assembly, while the kinetics of erosion seems independent.

Furthermore, results from both direct numerical simulations and laboratory experiments suggest that the erosion rate, for hole erosion and suffusion in granular matter, can also be interpreted as a function of the flow power according to a power law. Such a description of erosion requires only an evaluation of the global flow power (involving both the energy dissipated into heat and the energy transfered from the fluid to the solid phase), and not some of its components that could be more difficult to evaluate. The exponent of the power law is about 0.5 for the two-dimensional simulations of hole erosion, equal to one for the considered laboratory test of hole erosion, and slightly higher than 1.5 for the suffusion tests. This difference in the values of the exponent is still an open question. Concerning the case of piping erosion, the effect of the different flow regimes between the numerical model and laboratory tests should be investigated; for instance the spatial distribution of the viscous dissipation as displayed in Figure 11 may be affected by the flow regime. More generally the difference in the values of the exponent may also result from the two dimensionality of the numerical model, or from differences, between the suffusion and the piping erosion, in the physical processes related to the particle detachment and transport.

Finally, this study was restricted to particle detachment and transport steps. However, concerning 
suffusion, complementary analyses are necessary to describe the filtration step, possibly resulting in the development of overpressure of the interstitial fluid, and playing by this way an important role in the development of aggressive, quick and localized erosion processes, as shown in (Sail et al., 2011).

\section{Acknowledgement}

This research work was supported by the French Region Pays de la Loire through the project EMERMOD.

\section{References}

Araújo, A.D., Andrade, J.S., Herrmann, H.J., 2006. Critical role of gravity in filters. Phys. Rev. Lett. 97, 138001. URL: http://link.aps.org/doi/10.1103/PhysRevLett.97.138001, doi:10.1103/PhysRevLett.97.138001.

Bagnold, R., 1956. The flow of cohesionless grains in fluids. Philosophical Transactions of the Royal Society of London. Series A, Mathematical and Physical Sciences 249, 235-297.

Bagnold, R., 1980. An empirical correlation of bedload transport rates in flumes and natural rivers. Proc. R. Soc. Lond. A $372,453-473$.

Béguin, R., 2011. Etude multi-échelle de l'érosion de contact au sein des ouvrages hydrauliques en terre. Ph.D. thesis. Université de Grenoble.

Beguin, R., Philippe, P., Faure, Y., 2013. Pore-scale flow measurements at the interface between a sandy layer and a model porous medium: Application to statistical modeling of contact erosion. J. Hydraulic Engineering 139, 1-11.

Bhatnagar, P., Gross, E., Krook, M., 1954. A Model for Collision Processes in Gases. I. Small Amplitude Processes in Charged and Neutral One-Component Systems. Phys. Rev. 94, 511-525. doi:10.1103/PhysRev.94.511.

Bonelli, S. (Ed.), 2012. Erosion in Geomechanics Applied to Dams and Levees, ISTE-Wiley.

Bonelli, S., Brivois, O., 2008. The scaling law in the hole erosion test with a constant pressure drop. Int. J. Numer. Anal. Meth. Geomech. 32, 1573-1595.

Bonelli, S., Marot, D., 2011. Micromechanical modeling of internal erosion. European Journal of Environmental and Civil Engineering 15, 1207-1224.

Briaud, J., Ting, F., Chen, H., Cao, Y., Han, S., Kwak, K., 2001. Erosion function apparatus for scour rate predictions. Journal of Geotechnical and Geoenvironmental Engineering 127, 105-113. doi:10.1061/(ASCE)1090-0241(2001)127:2(105).

Chang, D., Zhang, L., 2011. A stress-controlled erosion apparatus for studying internal erosion in soils. Geotechnical Testing Journal 34, 579-589.

Chareyre, B., Cortis, A., Catalano, E., Barthélemy, E., 2012. Pore-scale modeling of viscous flow and induced forces in dense sphere packings. Transport in Porous Media 92, 473-493. URL: http://dx.doi.org/10.1007/s11242-011-9915-6, doi:10.1007/s11242-011-9915-6.

Chen, H., Chen, S., Matthaeus, W., 1992. Recovery of the Navier-Stokes equations using a lattice-gas Boltzmann method. Physical Review A 45, R5339-R5342. URL: http://pra.aps.org/abstract/PRA/v45/i8/pR5339_1, doi:10.1103/PhysRevA.45.R5339.

Cundall, P., Strack, O., 1979. A discrete numerical model for granular assemblies. Geotechnique 29, 47-65.

Fell, R., Fry, J.J. (Eds.), 2007. Internal erosion of dams and their foundations, Taylor \& Francis Publisher.

Feng, Y., Han, K., Owen, D., 2007. Coupled lattice Boltzmann method and discrete element modelling of particle transport in turbulent fluid flows: Computational issues. International Journal for Numerical Methods in Engineering 72, 1111-1134.

Ferro, V., 1998. Evaluating overland flow sediment transport capacity. Hydrological Processes 12, 1895-1910. 
Govers, G., 1992. Evaluation of transporting capacity formulae for overland flow, in: Parsons, A., Abrahams, A. (Eds.), Overland flow, UCL Press, London. pp. 243-273.

Guyon, E., Hulin, J., L., P., 2001. Hydrodynamique physique. EDP Sciences / CNRS Editions.

Haghighi, I., Chevalier, C., Duc, M., Guédon, S., Reiffsteck, P., 2013. Improvement of hole erosion test and results on reference soils. Journal of Geotechnical and Geoenvironmental Engineering 139, 330-339. doi:10.1061/(ASCE)GT.1943-5606.0000747.

Ladd, A., 1994. Numerical simulations of particulate suspensions via a discretized Boltzmann equation. Part 1. Theoretical foundation. Journal of Fluid Mechanics 271, 285.

Lominé, F., Scholtès, L., Sibille, L., Poullain, P., 2013. Modelling of fluid-solid interaction in granular media with coupled lb/de methods: application to piping erosion. Int. J. Numer. Anal. Meth. Geomech. 37, 577-596. Doi: 10.1002/nag.1109.

Low, H., 1989. Effect of sediment density on bed-load transport. Journal of Hydraulic Engineering 115, 124-138.

Marot, D., Bendahmane, F., Rosquoet, F., Alexis, A., 2009. Internal flow effects on isotropic confined sand-clay mixtures. Soil \& sediment contamination 18, 294-306.

Marot, D., Le, V., Garnier, J., Thorel, L., Audrain, P., 2012. Study of scale effect in an internal erosion mechanism: centrifuge model and energy analysis. European Journal of Environmental and Civil Engineering 16, 1-19.

Marot, D., Regazzoni, P., Wahl, T., 2011. Energy-based method for providing soil surface erodibility rankings. J. Geotech. Geoenviron. Eng. 137, 1290-1293.

Moffat, R., Fannin, J., 2006. A large permeameter for study of internal stability in cohesionless soils. Geotechnical Testing Journal 29, 273-279.

Nguyen, H., Marot, D., Bendahmane, F., 2012. Erodibility characterisation for suffusion process in cohesive soil by two types of hydraulic loading. La Houille Blanche, International Water Journal 6, 54-60.

Parchure, T., Mehta, A., 1985. Erosion of soft cohesive sediment deposits. Journal of Hydraulic Engineering 111, $1308-1326$. doi:10.1061/(ASCE)0733-9429(1985)111:10(1308).

Partheniades, E., 1965. Erosion and deposition of cohesive soils. Journal of the Hydraulics Division 91, $105-139$.

Perzlmaier, S., 2007. Hydraulic criteria for internal erosion in cohesionless soil, in: Fell, R., Fry, J.J. (Eds.), Internal erosion of dams and their foundations, Taylor \& Francis. pp. 179-190.

Qian, Y., D'Humieres, D., Lallemand, P., 1992. Lattice BGK Models for Navier-Stokes Equation. EPL (Europhysics Letters) $17,479-484$

Reddi, L., Lee, I., Bonala, M., 2000. Comparison of internal and surface erosion using flow pump test on a sand-kaolinite mixture. Geotechnical Testing Journal 23, 116-122.

Regazzoni, P., Marot, D., 2013. A comparative analysis of interface erosion tests. Natural hazards 67, 937-950. Doi:10.1007/s11069-013-0620-3.

Rogoz, M., 1985. Seepage power as a factor determining the piping and silting up the loose water-bearing soils, in: FernándezRubio, R. (Ed.), Proceedings, 2nd International Mine Water Association Congress, School of Mines, Department of Hydrogeology, Granada. pp. 221-229.

Sail, Y., Marot, D., Sibille, L., Alexis, A., 2011. Suffusion tests on cohesionless granular matter. European Journal of Environmental and Civil Engineering 15, 799-817.

Sjah, J., Vincens, E., 2013. Determination of the constriction size distribution of granular filters by filtration tests. International Journal for Numerical and Analytical Methods in Geomechanics 37, 1231-1246. URL: http://dx.doi.org/10.1002/nag.2076, doi:10.1002/nag.2076.

Skempton, A., Brogan, J., 1994. Experiments on piping in sandy gravels. Géotechnique 44, 440-460.

Steeb, H., Diebels, S., 2003. A thermodynamic-consistent model describing growth and remodeling phenomena. Computational Materials Science 28, 597-607. doi:http://dx.doi.org/10.1016/j.commatsci.2003.08.016.

Sterpi, D., 2003. Effects of the erosion and transport of fine particles due to seepage flow. International Journal of Geomechanics 
3, 111-122.

Succi, S., 2001. The Lattice Boltzmann Equation for Fluid Dynamics and Beyond. Oxford University Press.

Wan, C., Fell, R., 2004. Investigation of internal erosion and piping of soils in embankment dams by the slot erosion test and the hole erosion test. UNICIV Report 412. University of New South Wales.

Zeghal, M., El Shamy, U., 2004. A continuum-discrete hydromechanical analysis of granular deposit liquefaction. International Journal for Numerical and Analytical Methods in Geomechanics 28, 1361-1383. 


\begin{tabular}{|l|l|}
\hline $\begin{array}{l}\text { DE method } \\
\text { (for a particle diameter } d \text { ) }\end{array}$ & LB method \\
\hline$k_{n} / d=150 \times 10^{6} \mathrm{Nm}^{-2}$ & $\nu=10^{-6} \mathrm{~m}^{2} / \mathrm{s}$ \\
$k_{n} / k_{s}=0.4$ & $\rho_{0}=1000 \mathrm{~kg} \mathrm{~m}^{-3}$ (fluid density) \\
$\phi=20 \mathrm{deg}$ & \\
$C_{n} / d=C_{s} / d=C / d=0.152$ to $12.7 \mathrm{~N} / \mathrm{m}$ & \\
$\rho_{p}=2600 \mathrm{~kg} / \mathrm{m}^{-3}$ (particle density) & \\
\hline
\end{tabular}

Table 1: Mechanical parameter values for the coupled DE-LB method.

\begin{tabular}{|l|l|l|l|l|l|l|l|l|}
\hline Authors & $\mathrm{n}$ & $\begin{array}{l}\mathrm{k} \\
(\mathrm{m} / \mathrm{s})\end{array}$ & $i$ & $\begin{array}{l}\mathrm{Q} \\
\left(\mathrm{m}^{3} / \mathrm{s}\right)\end{array}$ & $\begin{array}{l}\max \left(q_{s}\right) \\
(\mathrm{mg} / \mathrm{s})\end{array}$ & $\begin{array}{l}\text { Flow power } \\
P_{F}(\mathrm{~W})\end{array}$ & $\begin{array}{l}P k_{\text {solid }} \\
(\mathrm{W})\end{array}$ & $\begin{array}{l}P t_{\text {solid }} \\
(\mathrm{W})\end{array}$ \\
\hline Marot et al. & 0.33 & $510^{-6}$ & 8 & $7.8510^{-8}$ & 0.9 & $3.1410^{-4}$ & $6.5910^{-14}$ & $4.4110^{-6}$ \\
\hline $\begin{array}{l}\text { Chang \& } \\
\text { Zhang }\end{array}$ & 0.307 & $1210^{-5}$ & 3.15 & $2.9710^{-6}$ & 24.8 & $9.3610^{-3}$ & $1.8810^{-11}$ & $2.4310^{-5}$ \\
\hline Sail et al. & 0.27 & - & 3.0 & $1.6710^{-5}$ & 369 & 0.225 & $1.8510^{-4}$ & $1.6210^{-3}$ \\
\hline
\end{tabular}

Table 2: Estimation, from laboratory tests of suffusion, of the power transfered from the fluid to the detached solid particles, assumed to be composed of a kinetic power term $P k_{\text {solid }}$ and a transport term $P t_{\text {solid }}$.

\begin{tabular}{|l|l|l|l|l|l|}
\hline Soil & $\begin{array}{l}\max \left(q_{s}\right) \\
(\mathrm{kg} / \mathrm{s})\end{array}$ & $\begin{array}{l}\mathrm{Q} \\
\left(\mathrm{m}^{3} / \mathrm{s}\right)\end{array}$ & $\begin{array}{l}\text { Flow power } \\
P_{F}(\mathrm{~W})\end{array}$ & $\begin{array}{l}P k_{\text {solid }} \\
(\mathrm{W})\end{array}$ & $\begin{array}{l}\text { Pt solid } \\
(\mathrm{W})\end{array}$ \\
\hline TF-2 & $3.710^{-4}$ & $910^{-5}$ & 1.25 & $2.4510^{-4}$ & $3.6310^{-4}$ \\
\hline L-1 & $2.310^{-3}$ & $310^{-5}$ & 0.01 & $1.6810^{-4}$ & $2.2510^{-3}$ \\
\hline
\end{tabular}

Table 3: Estimation from hole erosion tests reported in (Regazzoni and Marot, 2013) of the power transfered from the fluid to the detached solid particles, assumed to be composed of a kinetic power term $P k_{\text {solid }}$ and a transport term $P t_{\text {solid }}$. 


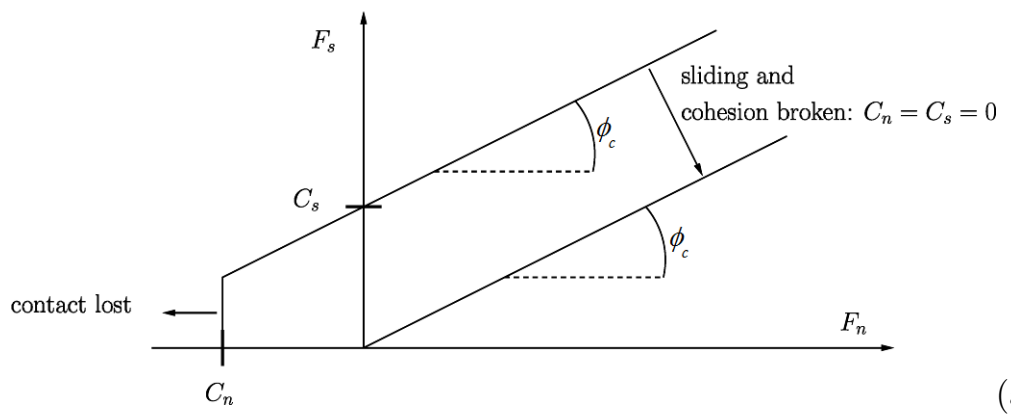

(a)

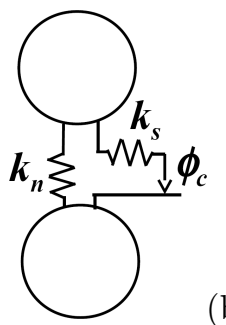

(b)

Figure 1: Failure criterion of the inter-particle contacts in the tangential versus normal force plane (a), and rheological model of the contact law (b).

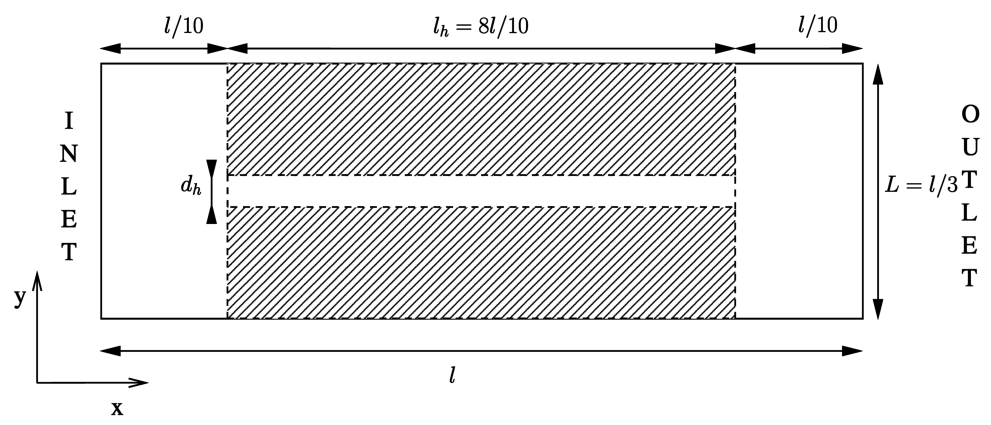

Figure 2: Sketch of the numerical model. Hatched regions correspond to the locations of the cohesive granular assembly such that an initial horizontal hole is formed $\left(l=0.03 \mathrm{~m}, d_{h} \approx 0.002 \mathrm{~m}\right)$. 


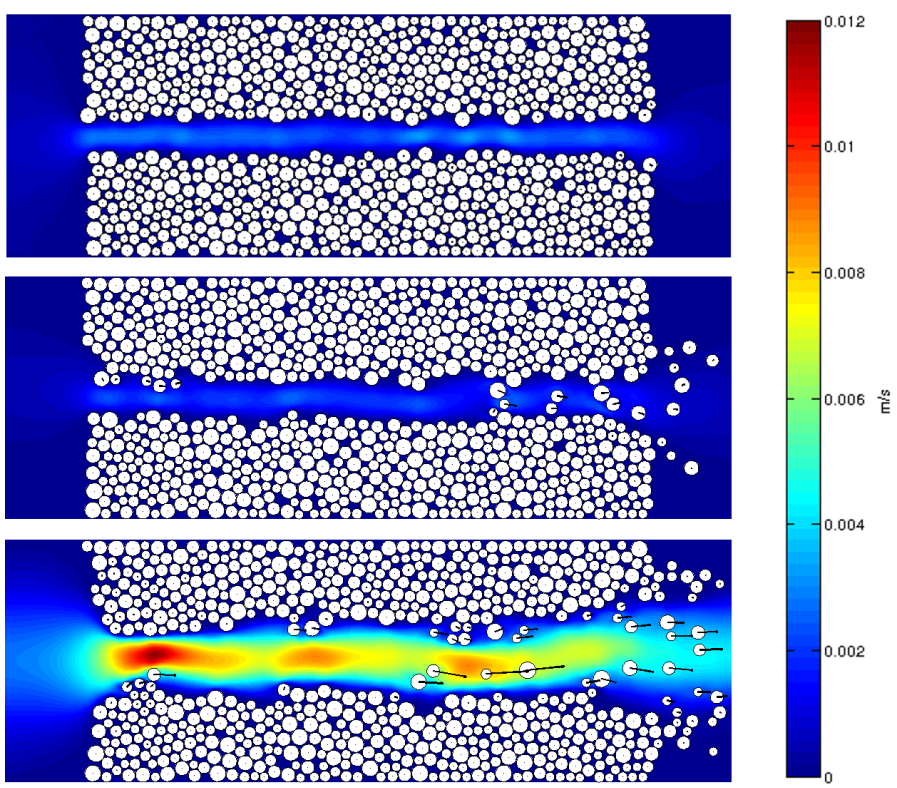

Figure 3: Snapshots at times $t=0.7 ; 13.3$ and $55.0 \mathrm{~s}$ of an erosion simulation for a pressure drop $\Delta P=0.3 \mathrm{~Pa}$ and a cohesion $C / d=1.27 \mathrm{~N} / \mathrm{m}$, the color scale is related to the fluid velocity, whereas the translation velocity of solid particles is represented with arrows.

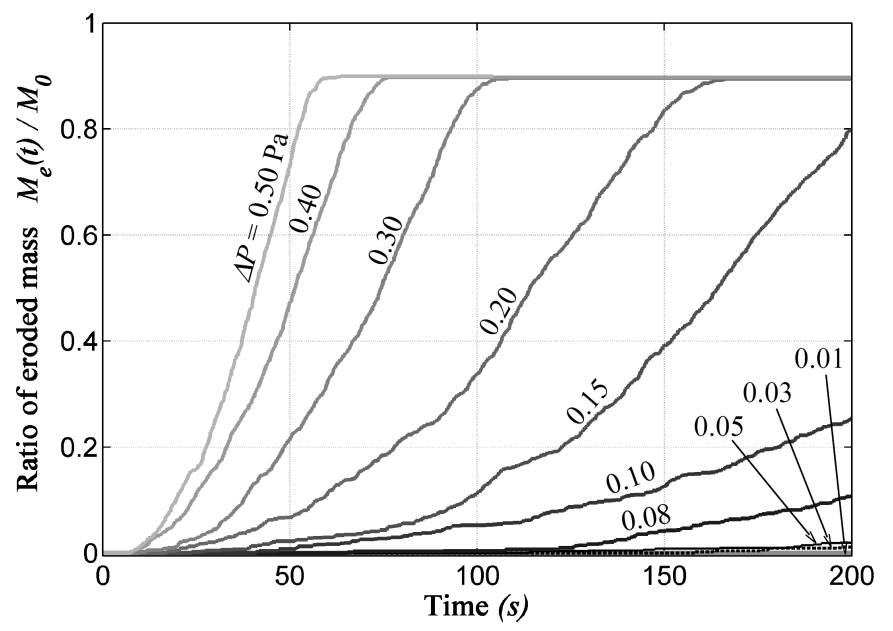

Figure 4: Time series of ratio of eroded mass $M_{e}(t) / M_{0}$ for an inter-particle cohesion $C / d=0.506 \mathrm{~N} / \mathrm{m}$ simulated for ten different values of pressure drop $\Delta P$ ranging from 0.01 to $0.50 \mathrm{~Pa}$. 


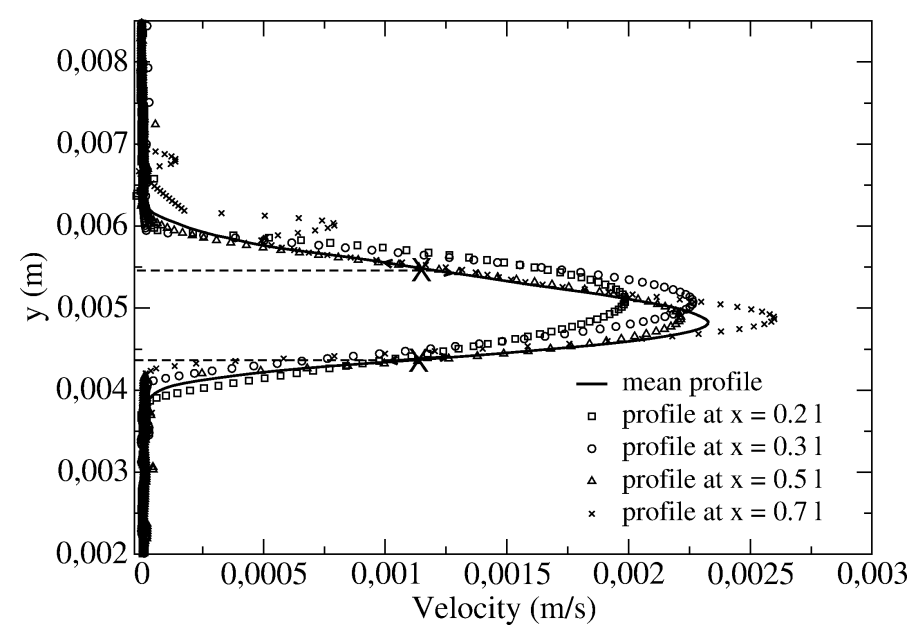

Figure 5: Cross profiles of the fluid velocity $V_{x}$ in the hole for $C / d=1.27 \mathrm{~N} / \mathrm{m}$ and $\Delta P=0.3 \mathrm{~Pa}$ at $t=24.7 \mathrm{~s}$, points where velocity gradient is computed to estimate the hydraulic shear stress $\tau_{s}$ are represented with big cross symbols.
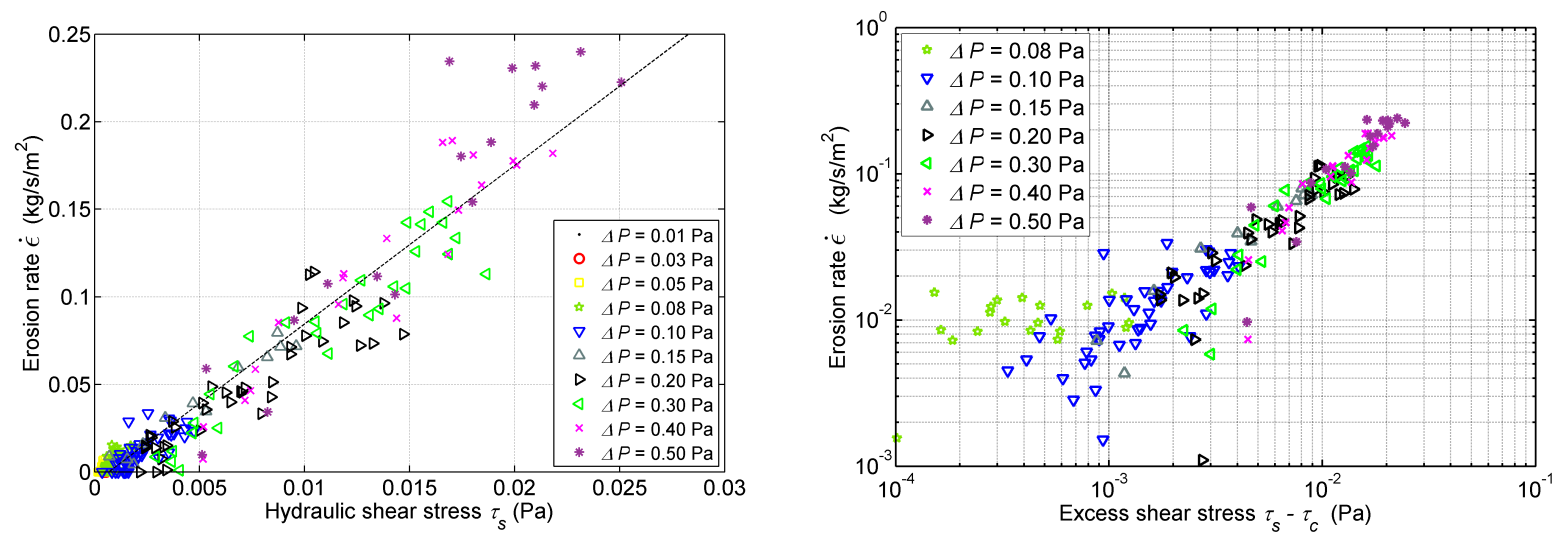

Figure 6: Erosion rate simulated with respect to the hydraulic shear stress estimated on upper and bottom hole boundaries for $C / d=0.506 \mathrm{~N} / \mathrm{m}$, in linear scale on the left (with the plot of the linear regression), and in logarithmic scale on the right with respect to the excess shear stress $\tau_{s}-\tau_{c}$ (values lower than threshold $\tau_{c}$ have been removed from this last diagram). 

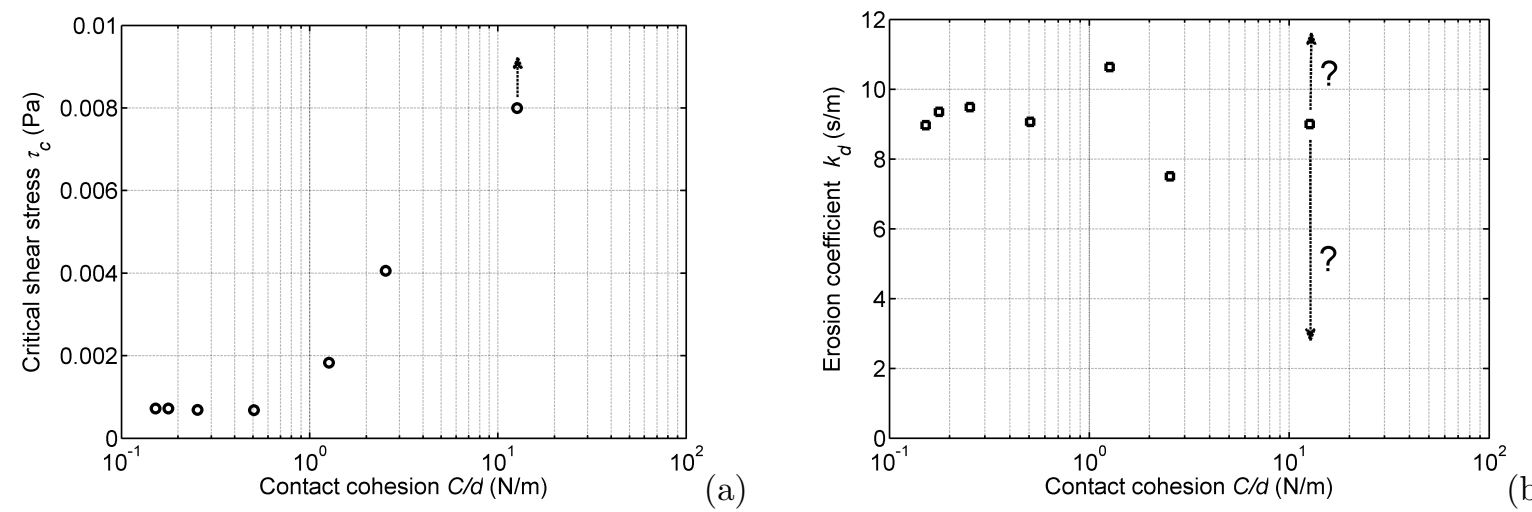

Figure 7: Influence of the inter-particle cohesion $C$ on the critical shear stress $\tau_{c}$ (a), and the erosion coefficient $k_{d}$ (b), each point is deduced from five to ten simulations performed with pressure drops $\Delta P$ ranging from 0.01 to $0.50 \mathrm{~Pa}$.

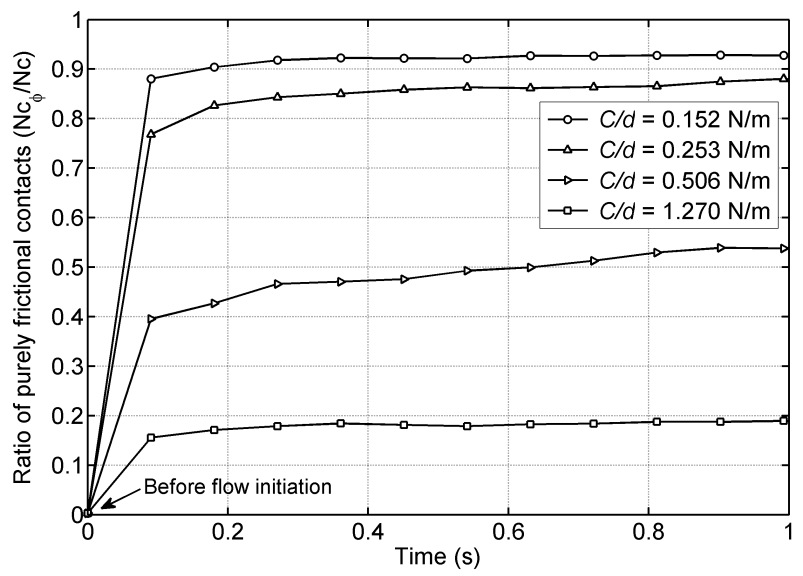

Figure 8: Ratio of frictional contacts $N c_{\phi} / N c$ (i.e. contacts with broken cohesion) during the first second of simulation; results computed with $\Delta P=0.15 \mathrm{~Pa}$ and $C / d=0.152 ; 0.253 ; 0.506$ and $1.27 \mathrm{~N} / \mathrm{m}$. 

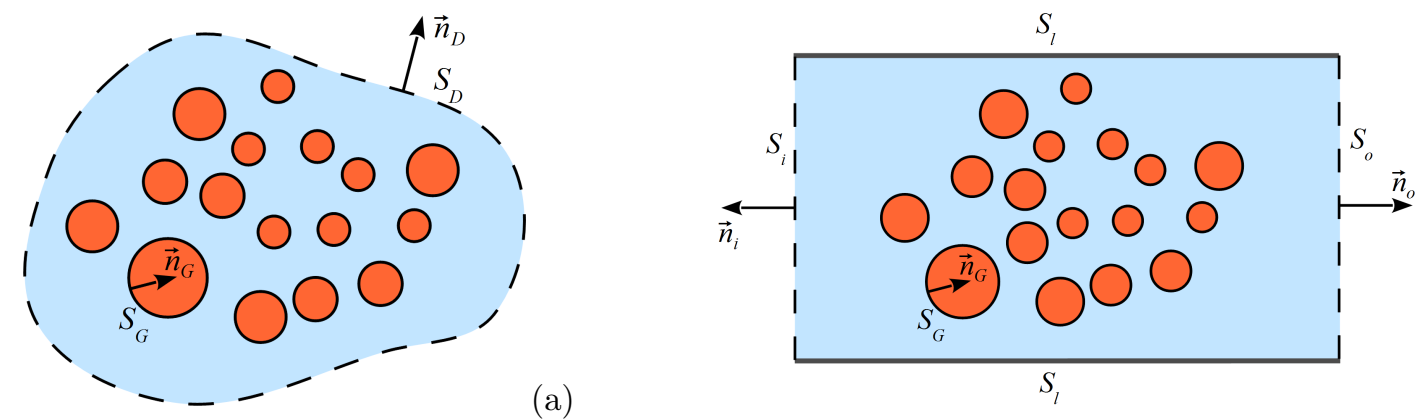

(b)

Figure 9: Outer fluid boundary $S_{D}$ and grain boundary $S_{G}$ for a seepage within a granular assembly (a), and decomposition of the outer fluid boundary in lateral $S_{l}$, inlet $S_{i}$ and outlet $S_{o}$ surfaces in the case of a tube of constant section (b).
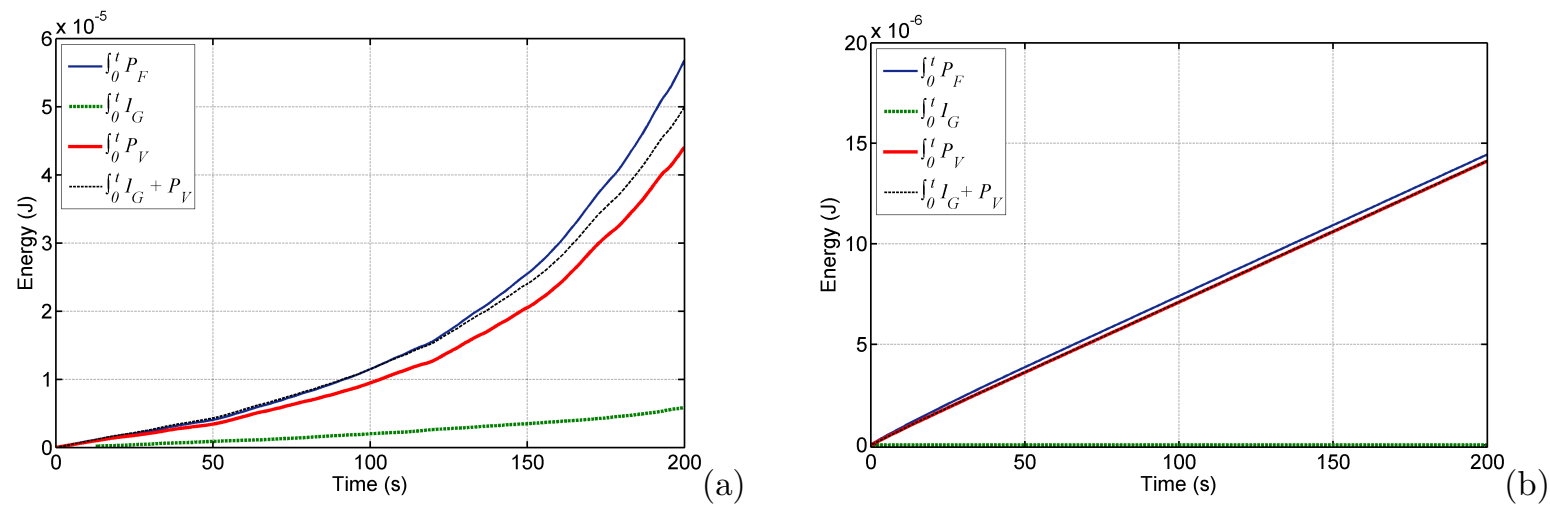

Figure 10: Comparison of energetic terms (flow power $P_{F}$, transfer power from fluid to solid $I_{G}$, and power dissipated by viscosity $P_{V}$ ) for erosion simulations with the coupled numerical model, with an inter-particle cohesion $C / d=0.253 \mathrm{~N} / \mathrm{m}(\mathrm{a})$, and $C / d=2.53 \mathrm{~N} / \mathrm{m}(\mathrm{b})$, under a pressure drop $\Delta P=0.1 \mathrm{~Pa}$. 

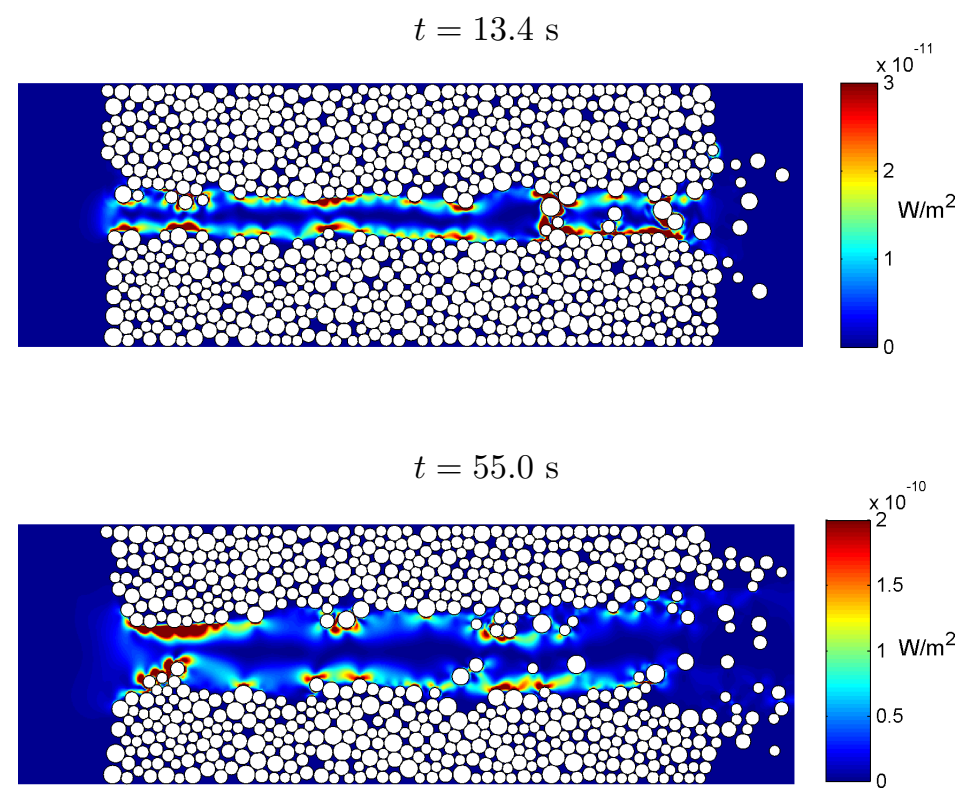

Figure 11: Field of density of power dissipated by viscosity $P_{V}$ at $t=13.4$ and $55.0 \mathrm{~s}$ for the simulation with $C / d=1.27 \mathrm{~N} / \mathrm{m}$ and $\Delta P=0.30 \mathrm{~Pa}$.

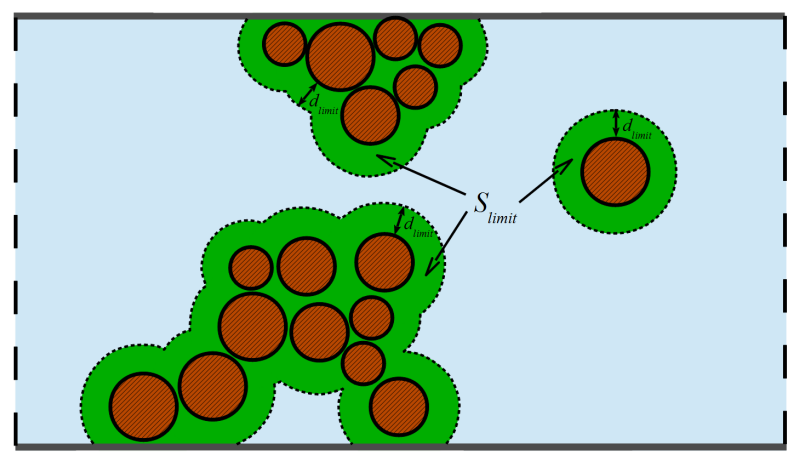

Figure 12: Definition of the surface $S_{\text {limit }}$ over which is integrated the viscous power density to compute $P_{V}\left(\in S_{\text {limit }}\right)$. 


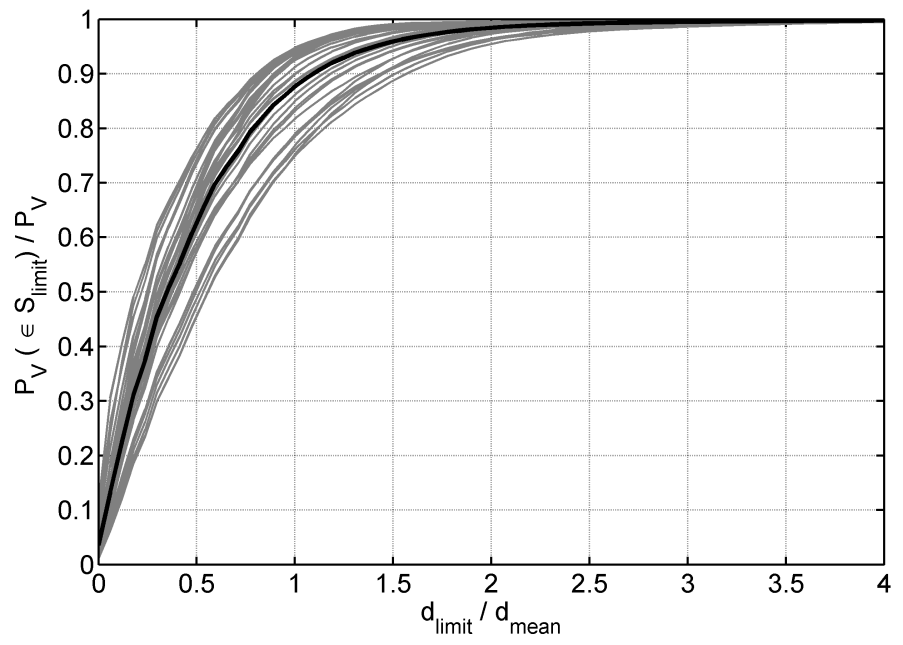

Figure 13: Ratio of the viscous power dissipated in surface $S_{\text {limit }}$ with respect to the normalized distance $d_{\text {limit }} / d_{\text {mean }}$ from the solid/fluid interface, for $C / d=1.27$ and $\Delta P=0.3 \mathrm{~Pa}$; the black curve is an average of grey ones plotted at different simulation times.
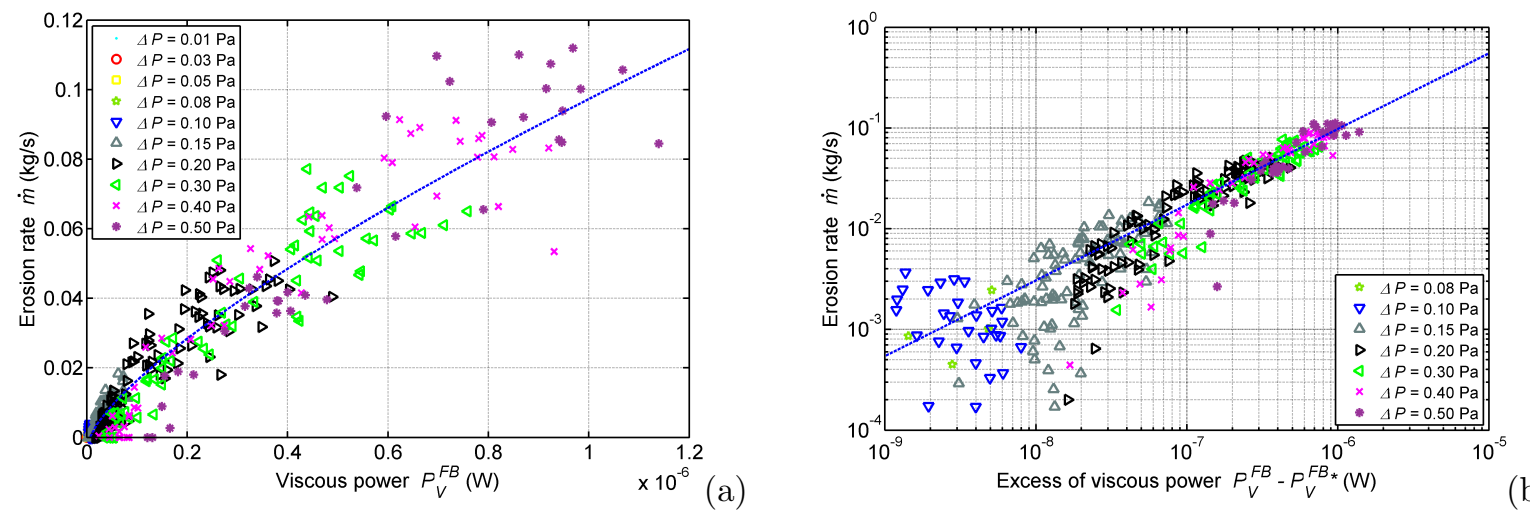

(b)

Figure 14: Erosion rate as a function of the power dissipated by viscosity at fluid boundary nodes $P_{V}^{F B}$ for $C / d=1.27 \mathrm{~N} / \mathrm{m}$. Dashed line represents an approximation with a power law (Eq. 9); data corresponding to the lowest pressure drops $\Delta P$ involving $P_{V}^{F B}$ values lower than threshold $P_{V}^{F B *}$ have been removed from the logarithmic diagram (b). 

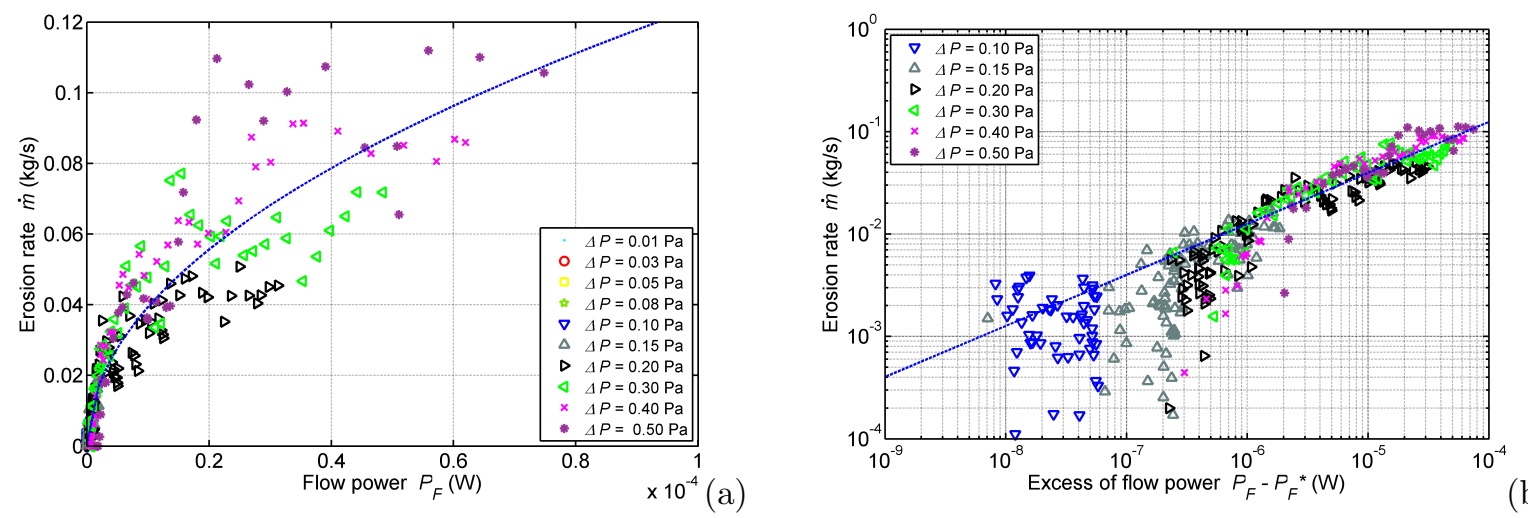

Figure 15: Erosion rate as a function of the flow power $P_{F}$ for $C / d=1.27 \mathrm{~N} / \mathrm{m}$. Dashed line represents an approximation with a power law (Eq. 10); data corresponding to the lowest pressure drops $\Delta P$ involving $P_{F}$ values lower than threshold $P_{F}^{*}$ have been removed from the logarithmic diagram (b).
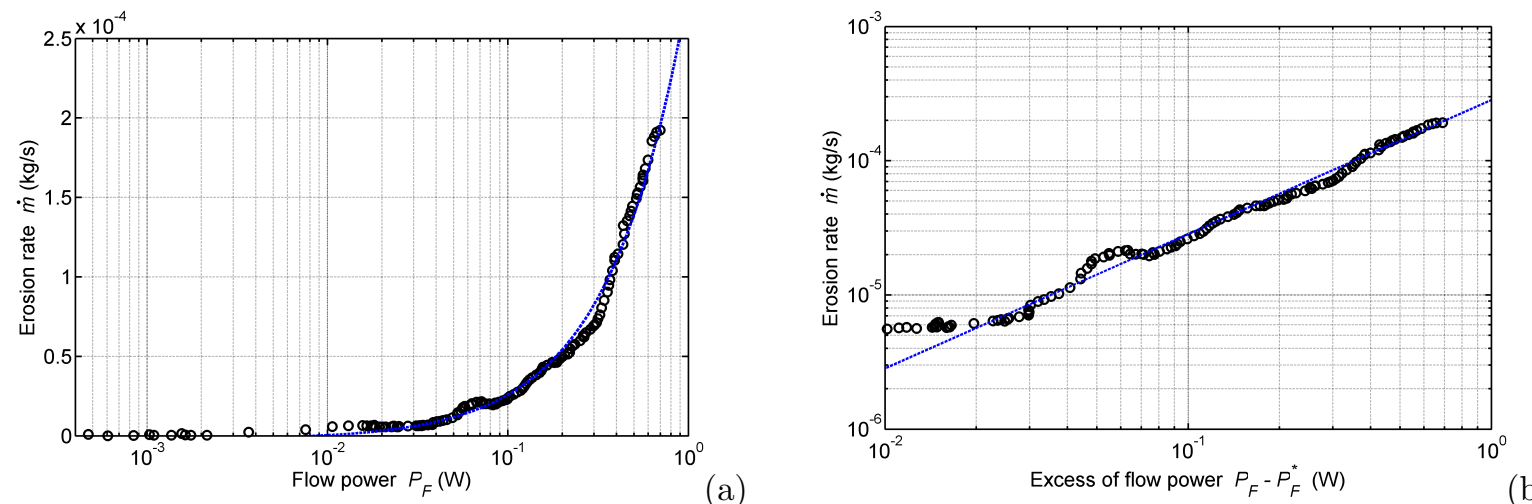

(a)

Figure 16: Erosion rate measured from a hole erosion test performed by Haghighi et al. (2013) on a mixture of clay and sand, represented as a function of the flow power. The dashed line represents a linear approximation involving a threshold flow power $P_{F}^{*}=8 \cdot 30^{-3} \mathrm{~W}$ identifiable in the semilogarithmic diagram (a). 


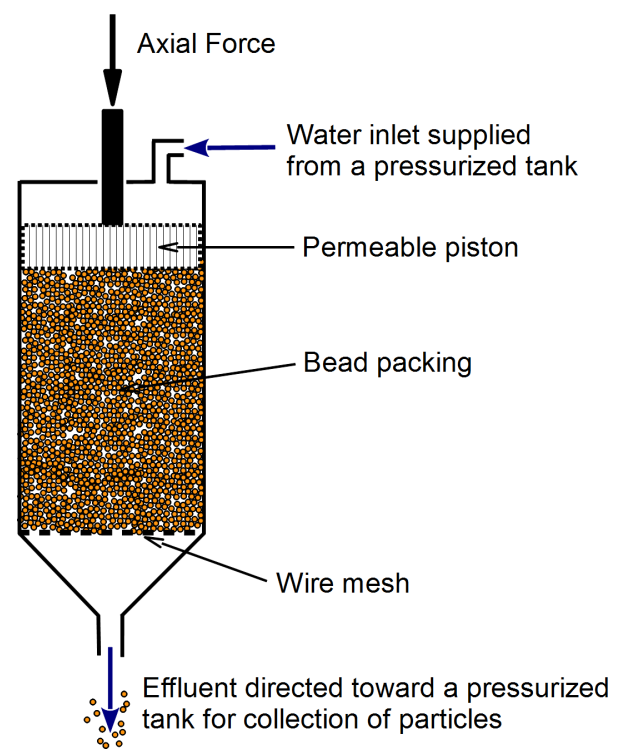

Figure 17: Sketch of the oedo-permeameter used to perform suffusion tests on glass bead assemblies.
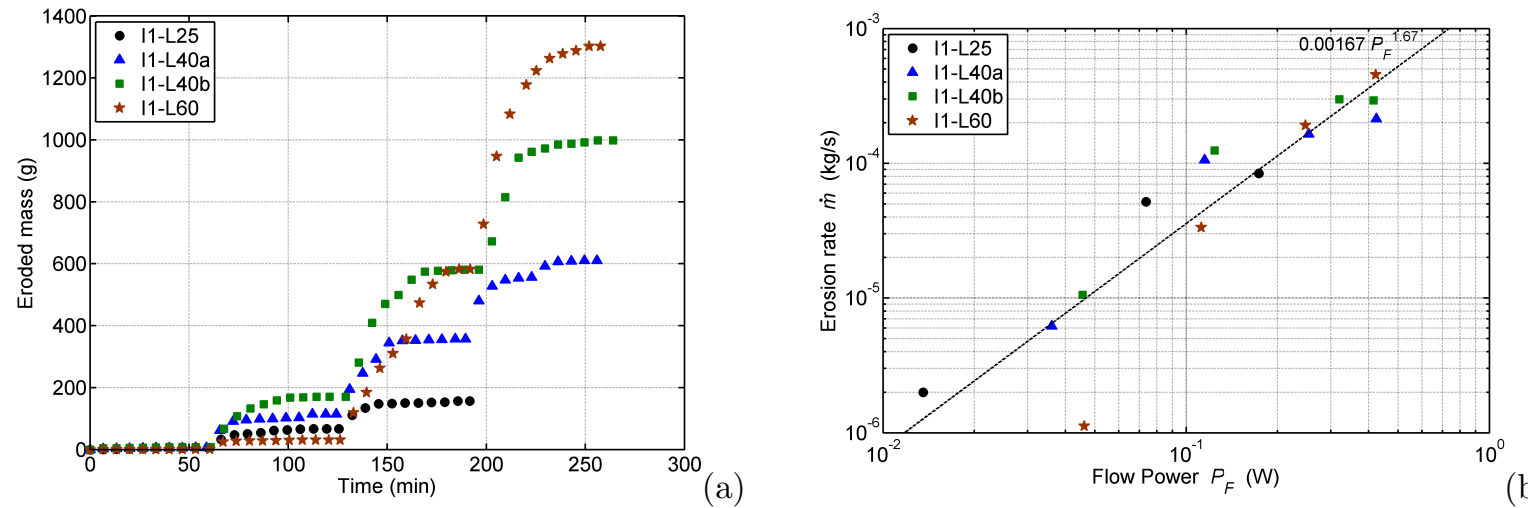

Figure 18: Erosion test on glass bead assemblies: mass of eroded particles with time (a), and erosion rate as a function of the flow power at initiation of hydraulic gradient steps (b); the dashed line represents an approximation with a power law 

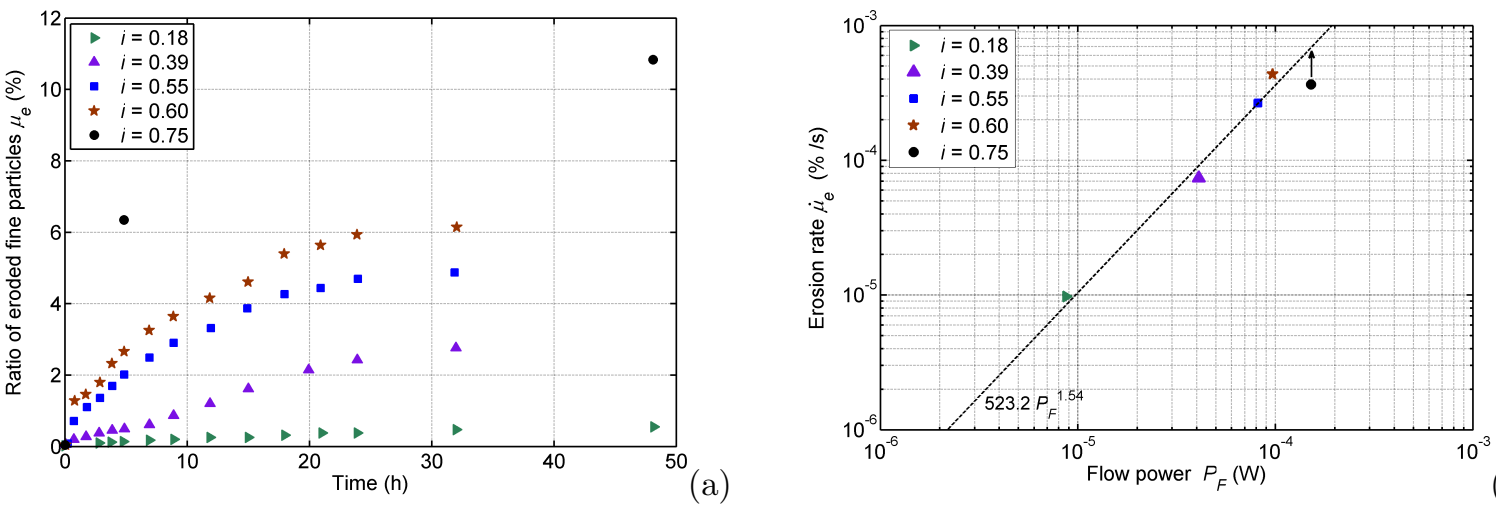

(b)

Figure 19: Erosion tests on natural soil: mass of eroded particles with time, after (Sterpi, 2003) (a), and erosion rate as a function of the flow power at test initiations. 